\title{
Association of perioperative blood pressure with long-term survival in rectal cancer patients
}

\author{
Hui-Chuan Yu ${ }^{1,2}$, Yan-Xin Luo ${ }^{1,2^{*}}$, Hui Peng ${ }^{1}$, Xiao-Lin Wang ${ }^{2}$, Zi-Huan Yang ${ }^{2}$, Mei-Jin Huang ${ }^{1}$, Liang Kang ${ }^{1}$, \\ Lei Wang ${ }^{1,2}$ and Jian-Ping Wang ${ }^{1,2^{*}}$
}

\begin{abstract}
Background: Several studies suggested that hypertension is positively related to cancer incidence and mortality. In this study, we investigated the association between perioperative blood pressure (BP) and long-term survival outcomes in patients with rectal cancer.

Methods: This study included a cohort of 358 patients with stages I-III rectal cancer who underwent a curative resection between June 2007 and June 2011. Both pre- and postoperative BPs were measured, by which patients were grouped (low BP: $<120 / 80 \mathrm{mmHg}$; high BP: $\geq 120 / 80 \mathrm{mmHg}$ ). The survival outcomes were compared between these two groups. The primary endpoints were disease-free survival (DFS) and cancer-specific survival (CSS).

Results: Univariate analysis showed that patients with high preoperative systolic BP had lower 3-year DFS (67.2\% vs. $82.1 \%, P=0.041)$ and CSS rates ( $81.9 \%$ vs. $94.8 \%, P=0.003)$ than patients with low preoperative systolic BP, and the associations remained significant in the Cox multivariate analysis, with the adjusted hazard ratios equal to 1.97 [95\% confidence interval $(\mathrm{Cl})=1.08-3.60, P=0.028]$ and $2.85(95 \% \mathrm{Cl}=1.00-8.25, P=0.050)$, respectively. Similarly, in postoperative evaluation, patients with high systolic BP had significantly lower 3-year CSS rates than those with low systolic BP (78.3\% vs. 88.9\%, $P=0.032)$ in univariate analysis. Moreover, high pre- and/or postoperative systolic BP presented as risk factors for CSS in the subgroups of patients who did not have a history of hypertension, with and/or without perioperative administration of antihypertensive drugs.
\end{abstract}

Conclusions: High preoperative systolic BP was an independent risk factor for both CSS and DFS rates, and high postoperative systolic BP was significantly associated with a low CSS rate in rectal cancer patients. Additionally, our results suggest that rectal cancer patients may get survival benefit from BP control in perioperative care. However, further studies should be conducted to determine the association between BP and CSS and targets of BP control.

Keywords: Blood pressure, Radical surgery, Rectal cancer, Cancer-specific survival

\section{Background}

Colorectal cancer is the third leading cause of cancerrelated death in the United States [1] and the fifth leading cause of cancer-related death in China, and its annual

\footnotetext{
*Correspondence: luoyx25@mail.sysu.edu.cn; wjp@mail.sysu.edu.cn 1 Department of Colon and Rectum Surgery, The Sixth Affiliated Hospital (Guangdong Gastrointestinal and Anal Hospital), Sun Yat-sen University, Guangzhou, Guangdong 510655, P. R. China

${ }^{2}$ Guangdong Provincial Key Laboratory of Colorectal and Pelvic Floor Disease, The Sixth Affiliated Hospital (Guangdong Gastrointestinal and Anal Hospital), Sun Yat-sen University, Guangzhou, Guangdong 510655, P. R. China

Full list of author information is available at the end of the article
}

incidence is increasing $[2,3]$. Therefore, many clinical and basic research studies have focused on the development of novel biomarkers to predict treatment outcomes and ensure optimal treatment allocation for patients with colorectal cancer [4]. Because of the increasing longevity rates and the increasing prevalence of obesity, hypertension has become a leading global disease [5]. A meta-analysis demonstrated a positive association between hypertension and all-site cancer incidence and mortality [6]. Moreover, many studies have reported this association for specific cancers, including renal carcinoma, which is the most common site-specific cancer 
[7]. Additional studies have shown that colorectal cancer risk is positively related to elevated blood pressure (BP) [8-12]. However, these findings were inconsistent, and in previous studies patients' BP was measured only at the time of baseline health examination. Furthermore, existing data are hampered by lack of adjustment for some potential confounding factors, such as tumor stage, tumor location, and the tumor's histologic features.

Against this background of inconsistent results and study limitations, we extended these findings by examining the association of perioperative BP with long-term survival outcomes in rectal cancer patients treated with radical-intent surgery. If a positive association does exist, efforts to control BP in perioperative care may lead to extended survival for these patients, which may in turn reveal new therapeutic targets and prognostic biomarkers.

\section{Patients and methods Patients}

We reviewed 556 patients with stages I-III rectal cancer who underwent radical surgery at our institution between June 2007 and June 2011. Rectal cancer was defined as histologically proven adenocarcinoma within $15 \mathrm{~cm}$ of the anal verge and was staged according to the 7th edition of the American Joint Committee on Cancer (AJCC) staging system [13], with staging procedures, including colonoscopy, contrast-enhanced computed tomography (CT) scans, and magnetic resonance imaging, performed at the initial diagnosis in all cases. The exclusion criteria were as follows: (1) absence of postoperative BP measured at 6:00 a.m. on two consecutive postoperative days; (2) familial adenomatous polyposis; and (3) multiple primary cancers. Of the 556 patients, 198 were excluded. Finally, this retrospective and longitudinal cohort study included 358 patients eligible for analysis (Fig. 1).

Demographic data (including age, height, and weight), tumor location, tumor staging, the tumor's histologic features, blood transfusion, preoperative serum carcinoembryonic antigen (CEA) level, treatment regimen, time-to-recurrence, and cancer-specific survival (CSS) were collected from the Institutional Cancer Database and the Department of Inpatient Medical Records. The study was approved by the Medicine Ethics Committee of the Six Affiliated Hospital at Sun Yat-sen University.

\section{Measurement of body mass index and BP}

For all patients, weight was measured in light indoor clothing, and height was measured without shoes. According to the World Health Organization recommendation for Asians based on obesity grade, body mass index (BMI) was categorized as underweight $\left(\right.$ BMI $\left.<18.5 \mathrm{~kg} / \mathrm{m}^{2}\right)$, normal (BMI 18.5-23 kg/m²), and overweight-obese (BMI $\left.\geq 23 \mathrm{~kg} / \mathrm{m}^{2}\right)$ [14]. Patients' preoperative BP was measured when they were admitted to the hospital. Postoperative BP was defined as the mean value of two BPs measured at 6:00 a.m. on 2 consecutive postoperative days (days 1 and 2). Resting time before BP measurement ranged from 10 to $20 \mathrm{~min}$, body position was sitting or supine, and the equipment used was a mercury sphygmomanometer or an automatic device. Hazard ratios (HRs) for long-term survival were calculated by levels of systolic blood pressure (SBP), diastolic blood pressure (DBP), and mid-BP [(SBP + DBP)/2]; SBP was also assessed in each subset by sex, BMI, and hypertension history. Mid-BP was primarily used because it is a strong predictor of cardiovascular mortality [15]. This measure, equally weighted for SBP and DBP, is considered an alternatively reasonable choice in the absence of knowledge about BP predictors in relation to rectal cancer. Pre- and postoperative BP results were classified using the Joint National Committee-7 definition of hypertension stage (BP: low <120/80 mmHg; high $\geq 120 / 80 \mathrm{mmHg}$ ) [16]. All patients were grouped according to these classifications.

\section{Treatment}

Details of chemoradiotherapy were described in our previous publication [17]. Among the 358 patients included in this study, 43 (12\%) received neoadjuvant chemoradiotherapy, in which a total irradiation dose of 46 Gy in 23 fractions of $2 \mathrm{~Gy}$ with concomitant application of 5-fluorouracil was given. At a median interval of 10.9 weeks (range, 6.9-17.3 weeks) after completion of chemoradiotherapy, total mesorectal excision (TME) for rectal cancer was implemented. Surgical techniques included low anterior resection, abdominoperineal resection, and the Parks procedure. Perioperative assessment of TME quality was performed on all surgical specimens. Based on physician suggestions and patient decisions, patients received 6-8 cycles of postoperative 5-fluorouracilbased chemotherapy, with a median interval of 4.4 weeks (range, 3.0-5.0 weeks).

\section{Follow-up}

All patients were re-evaluated every 3 months for the first 3 years after surgery, every 6 months for the next 2 years, and yearly thereafter. Each evaluation included a pertinent medical history, a physical examination (including a rectal examination), and measurement of serum CEA concentration. Routine radiologic examinations consisting of chest radiography, abdominopelvic CT or ultrasonography, whole-body bone scintigraphy, and colonoscopy or double-contrast barium enema were performed 6 months after surgery and annually thereafter. Cancer recurrence was detected by CEA $>5 \mathrm{ng} / \mathrm{mL}$ and/ 


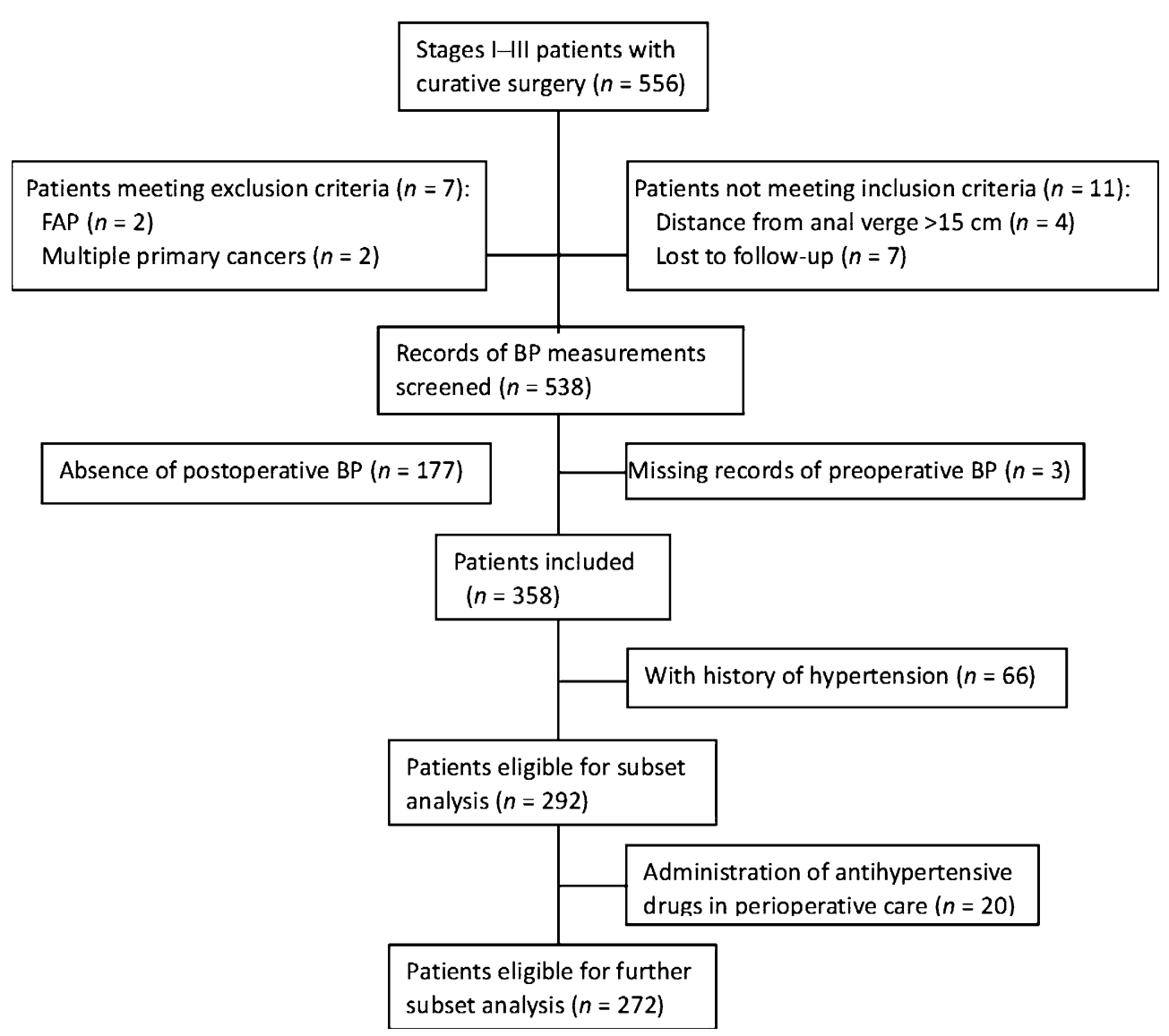

Fig. 1 Flow diagram of patient selection. This diagram presents case disposition in the analysis of the association between perioperative BP and long-term survival in patients with rectal cancer. BP blood pressure, FAP familial adenomatous polyposis

or a sequential CT scan with evidence of disease followed by histopathologic confirmation. The primary endpoints of this study were disease-free survival (DFS) and CSS. DFS was defined as the time from surgery until recurrence; CSS was defined as the time from surgery to death from rectal cancer. The designated endpoint date was July 2014, with the interval of follow-up ranging from 3 to 7 years. Patients were censored at their last follow-up if the endpoint of interest had not been met.

\section{Statistical analyses}

BPs were evaluated as both continuous and categorical variables using the median value. The intergroup comparisons of clinicopathologic variables were performed using the analysis of variance and Kruskal-Wallis tests for continuous variables (depending on the distribution of the continuous variables) and the Chi square and twotailed Fisher's exact tests for discrete variables. Postoperative survival was estimated using the Kaplan-Meier method. A univariate screening of potential risk factors of mortality using the Cox proportional hazards model for each variable extracted from medical records was performed. All significant risk factors in the univariate analysis were included in the multivariate analyses using the Cox proportional hazards model to identify independent risk factors. SBP, DBP, and mid-BP were never analyzed in the same model because of their multicollinearity. Data analysis was performed using SPSS version 22.0 software for Windows (SPSS, Inc., Chicago, IL, USA). All tests were two-sided, and $P<0.05$ were considered statistically significant.

\section{Results}

\section{Baseline characteristics}

Baseline demographic and clinicopathologic data of the entire cohort and each group by postoperative SBP are summarized in Table 1 . Of the 358 patients included in this study, 204 were men and 154 were women, with a median age of 60 years (range, $21-89$ years). Of the 358 patients, 199 (55.6\%) were categorized as underweight or normal weight, 135 (37.7\%) were categorized as overweight or obese, and $24(6.7 \%)$ had unknown 
Table 1 Baseline characteristics and distribution of clinicopathologic variables for the 358 patients with rectal cancer

\begin{tabular}{|c|c|c|c|c|}
\hline \multirow[t]{2}{*}{ Variable } & \multirow{2}{*}{$\begin{array}{l}\text { Overall population } \\
(n=358)\end{array}$} & \multicolumn{2}{|c|}{ Postoperative SBP (mmHg) } & \multirow[t]{2}{*}{$P$ value } \\
\hline & & $\begin{array}{l}<120 \\
(n=258)\end{array}$ & $\begin{array}{l}\geq 120 \\
(n=100)\end{array}$ & \\
\hline \multicolumn{5}{|l|}{ Age (years) } \\
\hline Median (range) ${ }^{\mathrm{a}}$ & $60(21-89)$ & $58(21-89)$ & $65(25-89)$ & $<0.001$ \\
\hline$<60$ & $174(48.6)$ & $143(55.4)$ & $31(31.0)$ & $<0.001$ \\
\hline$\geq 60$ & $184(51.4)$ & $115(44.6)$ & $69(69.0)$ & \\
\hline \multicolumn{5}{|l|}{ BMI $\left(\mathrm{kg} / \mathrm{m}^{2}\right)$} \\
\hline Median (range) ${ }^{\mathrm{a}}$ & $22.1(13.3-35.9)$ & $22.0(13.3-33.8)$ & $22.7(14.9-35.9)$ & 0.080 \\
\hline$<23$ & $199(55.6)$ & $152(58.9)$ & $47(47.0)$ & 0.219 \\
\hline$\geq 23$ & $135(37.7)$ & $95(36.8)$ & $40(40.0)$ & \\
\hline Unknown & $24(6.7)$ & $11(4.3)$ & $13(13.0)$ & \\
\hline Sex & & & & 0.631 \\
\hline Men & $204(57.0)$ & $145(56.2)$ & $59(59.0)$ & \\
\hline Women & $154(43.0)$ & $113(43.8)$ & $41(41.0)$ & \\
\hline History of hypertension & & & & $<0.001$ \\
\hline No & $292(81.6)$ & $233(90.3)$ & $59(59.0)$ & \\
\hline Yes & $66(18.4)$ & $25(9.7)$ & $41(41.0)$ & \\
\hline History of smoking & & & & 0.001 \\
\hline No & $263(73.5)$ & $202(78.3)$ & $61(61.0)$ & \\
\hline Yes & $95(26.5)$ & $56(21.7)$ & $39(39.0)$ & \\
\hline \multicolumn{5}{|l|}{ Preoperative BP (mmHg) } \\
\hline Median (range) ${ }^{\mathrm{a}}$ & $123(73-201)$ & $120(73-184)$ & $135(97-201)$ & $<0.001$ \\
\hline$<120$ & $107(29.9)$ & $94(36.4)$ & $13(13.0)$ & $<0.001$ \\
\hline $120-140$ & $171(47.8)$ & $130(50.4)$ & $41(41.0)$ & \\
\hline$\geq 140$ & $72(20.1)$ & $30(11.6)$ & $42(42.0)$ & \\
\hline Unknown & $8(2.2)$ & $4(1.6)$ & $4(4.0)$ & \\
\hline TNM stage, AJCC & & & & 0.537 \\
\hline I & $93(26.0)$ & $71(27.5)$ & $22(22.0)$ & \\
\hline$\|$ & $115(32.1)$ & $80(31.0)$ & $35(35.0)$ & \\
\hline III & $150(41.9)$ & $107(41.5)$ & $43(43.0)$ & \\
\hline Differentiation degree & & & & 0.353 \\
\hline Low & $68(19.0)$ & $47(18.2)$ & $21(21.0)$ & \\
\hline Moderate & $188(52.5)$ & $132(51.2)$ & $56(56.0)$ & \\
\hline High & $102(28.5)$ & $79(30.6)$ & $23(23.0)$ & \\
\hline Vascular invasion & & & & 0.782 \\
\hline Negative & $327(91.3)$ & $235(91.1)$ & $92(92.0)$ & \\
\hline Positive & $31(8.7)$ & $23(8.9)$ & $8(8.0)$ & \\
\hline Perineural invasion & & & & 0.698 \\
\hline Negative & $326(91.1)$ & $234(90.7)$ & $92(92.0)$ & \\
\hline Positive & $32(8.9)$ & $24(9.3)$ & $8(8.0)$ & \\
\hline Preoperative CEA & & & & 0.382 \\
\hline Negative & $252(70.4)$ & $185(71.7)$ & $67(67.0)$ & \\
\hline Positive & $106(29.6)$ & $73(28.3)$ & $33(33.0)$ & \\
\hline Distance from anal verge (cm) & & & & 0.831 \\
\hline$<5$ & $132(36.9)$ & $96(37.2)$ & $36(36.0)$ & \\
\hline $5-12$ & $226(63.1)$ & $162(62.8)$ & $64(64.0)$ & \\
\hline Intraoperative blood transfusion & & & & 0.514 \\
\hline No & $311(86.9)$ & $226(87.6)$ & $85(85.0)$ & \\
\hline Yes & $47(13.1)$ & $32(12.4)$ & $15(15.0)$ & \\
\hline
\end{tabular}


Table 1 continued

\begin{tabular}{|c|c|c|c|c|}
\hline \multirow[t]{2}{*}{ Variable } & \multirow{2}{*}{$\begin{array}{l}\text { Overall population } \\
(n=358)\end{array}$} & \multicolumn{2}{|c|}{ Postoperative SBP $(\mathrm{mmHg})$} & \multirow[t]{2}{*}{$P$ value } \\
\hline & & $\begin{array}{l}<120 \\
(n=258)\end{array}$ & $\begin{array}{l}\geq 120 \\
(n=100)\end{array}$ & \\
\hline Estimation of blood loss in operation [median (range); $\mathrm{mL}]^{\mathrm{a}}$ & $100(15-3000)$ & $100(20-3000)$ & $100(15-1000)$ & 0.899 \\
\hline Adjuvant treatment & & & & 0.122 \\
\hline No & $177(49.4)$ & $121(46.9)$ & $56(56.0)$ & \\
\hline Yes & $181(50.6)$ & $137(53.1)$ & $44(44.0)$ & \\
\hline Neoadjuvant treatment & & & & 0.146 \\
\hline No & $315(88.0)$ & $223(86.4)$ & $92(92.0)$ & \\
\hline Yes & $43(12.0)$ & 35 (13.6) & $8(8.0)$ & \\
\hline
\end{tabular}

SBP systolic blood pressure, BMI body mass index, BP blood pressure, AJCC American Joint Committee on Cancer, CEA carcinoembryonic antigen

a These values are presented as median followed by a range in the parentheses; other values are presented as the number of cases with a percentage in the following parentheses

BMI. In the entire cohort, 66 patients (18.4\%) had a history of hypertension and long-term regular use of antihypertensive drugs; in the preoperative evaluation, 72 (20.1\%) were categorized as having systolic hypertension (SBP $\geq 140 \mathrm{mmHg}), 171(47.8 \%)$ as having systolic prehypertension (SBP $=120-140 \mathrm{mmHg}$ ), 107 (29.9\%) as having normal SBP (SBP < $120 \mathrm{mmHg}$ ), and $8(2.2 \%)$ had unknown BP. The postoperative SBP, DBP, and midBP were statistically distributed with medians of 109.5 (80.0-171.0), 65.0 (42.5-102.0), and 87.5 (64.5-122.3) $\mathrm{mmHg}$, respectively. The AJCC staging of rectal cancer in the entire cohort was distributed as $26.0 \%, 32.1 \%$, and $41.9 \%$ for stage I, II, and III, respectively. No statistically significant differences were found between patients with postoperative $\mathrm{SBP}<120$ and $\geq 120 \mathrm{mmHg}$ regarding demographic, morphometric, therapeutic regimen, and tumor characteristics; however, statistically significant differences were found in preoperative hypertension (42.0\% vs. $11.6 \%, P<0.001$ ) and history of hypertension (41.0\% vs. $9.7 \%, P<0.001$ ) between the high-postoperative SBP group and the low-postoperative SBP group.

\section{Univariate and multivariate analyses of survival}

Median follow-up time was 42 months (range, 37-85 months). Kaplan-Meier curves showed significantly lower 3 -year DFS rate $(67.2 \%$ vs. $82.1 \%, P=0.041)$ and CSS rate $(81.9 \%$ vs. $94.8 \%, P=0.003)$ in the highpreoperative SBP group than in the low-preoperative SBP group. Similarly, patients in the high-postoperative SBP group had a significantly lower 3-year CSS rate (78.3\% vs. $88.9 \%, P=0.032)$ than patients in the low-postoperative SBP group, whereas the difference in the DFS rate $(65.1 \%$ vs. $75.0 \%, P=0.326$ ) was not significant (Fig. 2).

Univariate analysis showed that old age, advanced AJCC stage, vascular invasion, perineural invasion, elevated CEA level, low rectal cancer, and high pre- and postoperative BP were all significantly associated with increased mortality (Tables 2, 3). Specifically, HRs for BP and survival for total cases and for patients in each subset are shown in Table 3. In preoperative evaluation, patients with high SBP had lower 3-year DFS and CSS rates compared with patients with low SBP, the HRs of which were 1.87 (95\% CI, 1.11-3.17, $P=0.019$ ) and 4.18 (95\% CI, $1.48-11.83, P=0.007)$, respectively; in postoperative evaluation, these HRs for SBP were 1.26 (95\% CI, 0.79$1.98, P=0.330)$ and 1.99 (95\% CI, 1.05-3.78, $P=0.035)$, respectively. The HR of the CSS rate for postoperative mid-BP was 2.34 (95\% CI 1.16-4.72, $P=0.018$ ).

In multivariate analysis, old age, advanced AJCC stage, perineural invasion, low rectal cancer, adjuvant treatment regimen, and high preoperative SBP (adjusted $\mathrm{HR}=1.97$, 95\% CI $=1.08-3.60, P=0.028$ ) were still significantly associated with 3-year DFS rate. Advanced AJCC stage, elevated preoperative CEA level, low rectal cancer, adjuvant treatment regimen, and high preoperative SBP (adjusted HR $=2.85,95 \% \mathrm{CI}=1.00-8.25, P=0.050$ ) had independently significant prediction value on 3-year CSS. Nevertheless, postoperative SBP did not remain significant in the model for either DFS or CSS (Table 4).

\section{Analyses on subsets of patients without history of hypertension}

Further subset analyses were conducted to determine if the above association between perioperative $\mathrm{BP}$ and survival depends on the long-term negative effect of patients' history of hypertension on tumorigenesis and cancer mortality. For 292 patients without a history of hypertension, the HRs of CSS for pre- and postoperative SBP were 3.84 (95\% CI, 1.34-11.05, $P=0.012)$ and 2.77 (95\% CI, 1.36-5.66, $P=0.005$ ), respectively, whereas 

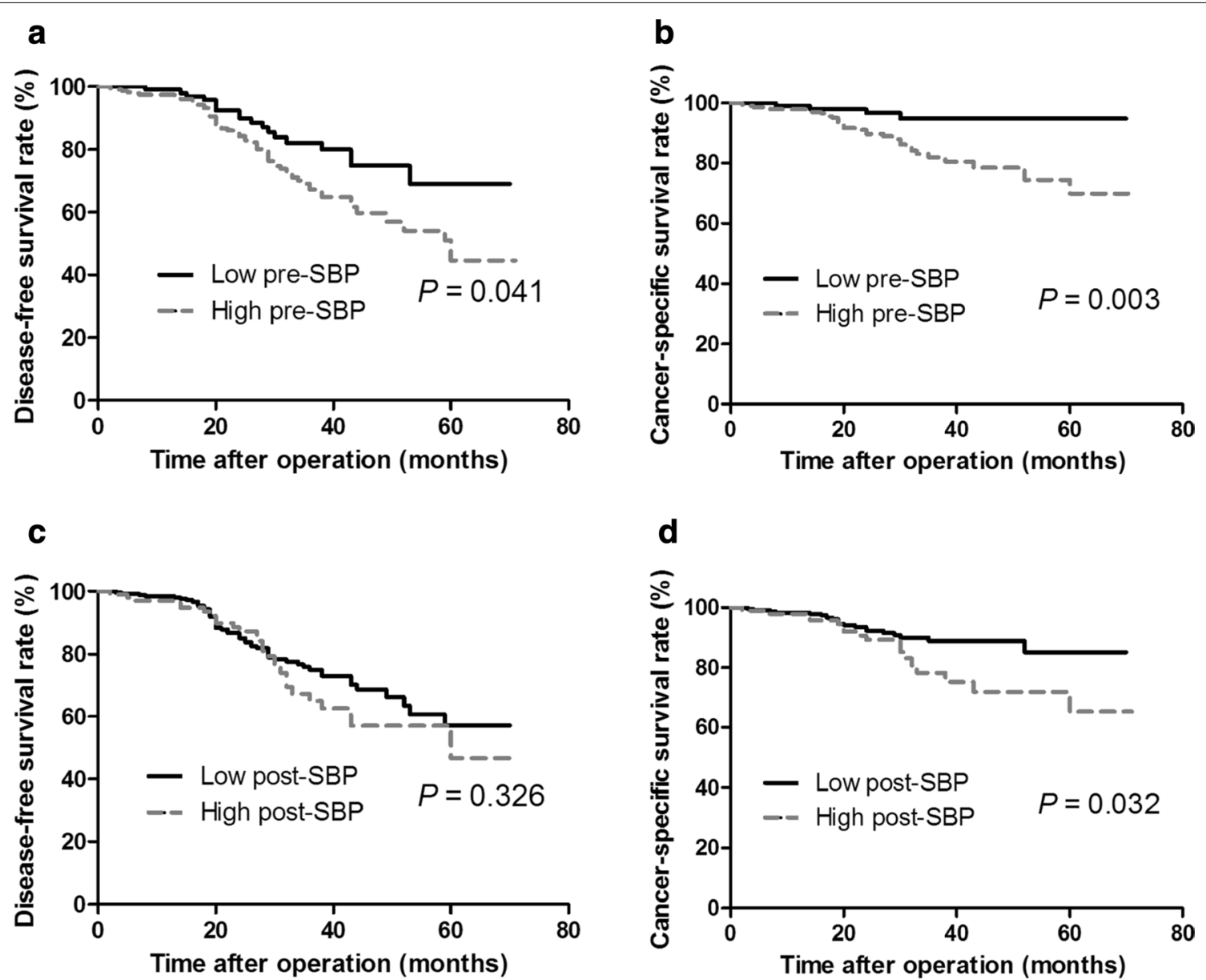

Fig. 2 Kaplan-Meier survival curves of rectal cancer patients with different preoperative and postoperative BPs. The curves showed significantly lower DFS (a) and CSS (b) rates in the high-preoperative SBP group than in the low-preoperative SBP group. Patients in the high-postoperative SBP group had significantly lower CSS (d) rates, whereas the differences in the DFS curves (c) were not significant. SBP systolic blood pressure, DFS disease-free survival, CSS cancer-specific survival

these associations were not significant in patients with a history of hypertension (Table 3). To further validate if the verified association with cancer risk depends on the negative effect of antihypertensive drugs, we excluded 86 patients with a history of hypertension and/or perioperative administration of antihypertensive drugs (Fig. 1); the survival outcomes were compared between the lowSBP group and the high-SBP group. In the analyses of the remaining 272 patients, the HRs were 3.36 (95\% CI, 1.159.84, $P=0.027)$ and 2.15 (95\% CI, 0.71-3.39, $P=0.076)$, respectively.

Other associations of SBPs were analyzed for DFS and/ or CSS among the subsets by sex and BMI (Table 3). In men, the HR of CSS for postoperative SBP was 3.37 (95\% CI, 1.00-11.39, $P=0.050$ ), whereas in women, the association was not significant. Interestingly, neither pre- nor postoperative SBP was significantly associated with survival in 135 patients with a BMI $\geq 23 \mathrm{~kg} / \mathrm{m}^{2}$.

\section{Discussion}

Our study showed that perioperative BP is negatively associated with survival outcome in patients with rectal cancer. In agreement with our hypothesis, 3-year CSS was associated with high pre- and postoperative BP in patients with rectal cancer treated with radical surgery, and high preoperative SBP was an independent risk factor. These findings were confirmed after we stratified patients and only looked at the tumors of patients without a history of hypertension.

The role of high BP as a possible risk factor for cancer mortality was first proposed in 1975 by Dyer et al. [10] and has since been examined in various cohort studies. In most studies, BP was measured at the time of the baseline health examination when patients were enrolled, and to date only Park's study-on renal carcinoma-addressed the association between perioperative BP and mortality [18]. However, the investigators examined the association 
Table 2 Univariate analysis of prognostic factors for DFS and CSS

\begin{tabular}{|c|c|c|c|c|c|c|}
\hline \multirow[t]{2}{*}{ Factor } & \multicolumn{3}{|l|}{ DFS } & \multicolumn{3}{|l|}{ CSS } \\
\hline & 3-year rate $(\%)$ & $\mathrm{HR}(95 \% \mathrm{Cl})$ & $P$ & 3-year rate (\%) & $\mathrm{HR}(95 \% \mathrm{Cl})$ & $P$ \\
\hline Age & - & $1.00(0.99-1.02)$ & 0.644 & - & $1.03(1.01-1.06)$ & 0.016 \\
\hline \multicolumn{7}{|c|}{ TNM stage, AJCC } \\
\hline III & 60.3 & $3.94(1.95-7.99)$ & $<0.001$ & 79.7 & $5.24(1.58-17.42)$ & 0.007 \\
\hline$\|$ & 79.7 & $1.81(0.82-4.01)$ & 0.142 & 86.6 & $3.14(0.88-11.24)$ & 0.079 \\
\hline 1 & 84.4 & 1.00 & & 94.7 & 1.00 & \\
\hline \multicolumn{7}{|c|}{ Vascular invasion } \\
\hline Positive & 59.3 & $1.93(1.10-3.39)$ & 0.021 & 77.6 & $1.70(0.71-4.07)$ & 0.234 \\
\hline Negative & 73.7 & 1.00 & & 86.7 & 1.00 & \\
\hline \multicolumn{7}{|c|}{ Perineural invasion } \\
\hline Positive & 38.0 & $3.44(1.98-5.98)$ & $<0.001$ & 73.8 & $2.45(1.02-5.90)$ & 0.046 \\
\hline Negative & 75.4 & 1.00 & & 87.0 & 1.00 & \\
\hline \multicolumn{7}{|c|}{ Preoperative CEA (ng/mL) } \\
\hline$>5$ & 63.9 & $1.59(1.00-2.52)$ & 0.050 & 75.2 & $2.91(1.48-5.71)$ & 0.002 \\
\hline $0-5$ & 77.2 & 1.00 & & 92.2 & 1.00 & \\
\hline \multicolumn{7}{|c|}{ Distance from anal verge $(\mathrm{cm})$} \\
\hline $5-12$ & 75.5 & $0.59(0.37-0.92)$ & 0.021 & 89.3 & $0.47(0.24-0.92)$ & 0.028 \\
\hline$<5$ & 69.3 & 1.00 & & 82.0 & 1.00 & \\
\hline \multicolumn{7}{|c|}{ Adjuvant treatment } \\
\hline Yes & 77.6 & $0.76(0.49-1.18)$ & 0.226 & 90.0 & $0.49(0.25-0.94)$ & 0.031 \\
\hline No & 67.2 & 1.00 & & 80.7 & 1.00 & \\
\hline
\end{tabular}

DFS disease-free survival, CSS cancer-specific survival, $H R$ hazard ratio, $C I$ confidence interval, $S B P$ systolic blood pressure, $B M I$ body mass index, $B P$ blood pressure, AJCC American Joint Committee on Cancer, CEA carcinoembryonic antigen

between perioperative BP and renal carcinoma mortality without stratification by history of hypertension and adjustment for some potential confounding factors. Since it is well established that hypertension has an unfavorable effect on tumorigenesis and cancer mortality over a long period of time and that a history of hypertension is positively linked with perioperative BP, Park's study was not able to determine the association between perioperative BP and cancer risk. In our analyses on subsets of patients without a history of hypertension, the remained association between high perioperative SBP and CSS risk indicated that the efforts to control BP in perioperative care may extend survival for this population. However, we did not exclude the possibility that undiagnosed hypertension and hypertension developed after the surgery affected our results. Moreover, the targets for BP control should be determined in a larger cohort.

Many large trials have provided unassailable evidence that antihypertensive therapy lowers cardiovascular morbidity and mortality [19-21]. However, not all studies have demonstrated a significant association between antihypertensive treatment and overall mortality [22]; indeed, others have reported that the association is diminished over time [20]. Since then, many studies continued to report a putative link between antihypertensive drugs and cancer, with diuretics being the most frequently cited suspect. These findings thus prompt the question: is high BP associated with increased cancer mortality, or is the use of antihypertensive therapy implicated? After excluding the patients with a history of hypertension and perioperative administration of antihypertensive drugs, the analyses were repeated in our study. The results remained virtually unchanged. Since our results from a series of subset analyses suggested cancer mortality is associated with perioperative high BP, diuretics could be substituted for other classes of antihypertensive drugs, although diuretics are currently recommended as the first-line treatment for patients with hypertension [23].

The biological mechanisms that could account for the association between hypertension and elevated cancer mortality remain unclear. Studies have suggested that hypertension and malignancy might share several common biochemical pathways leading to proliferative abnormalities in vascular smooth muscle cells [24], increased level of inositol triphosphate and cytosolic calcium [25], and abnormalities in carcinogen binding to DNA in lymphocytes [26], which are associated with 


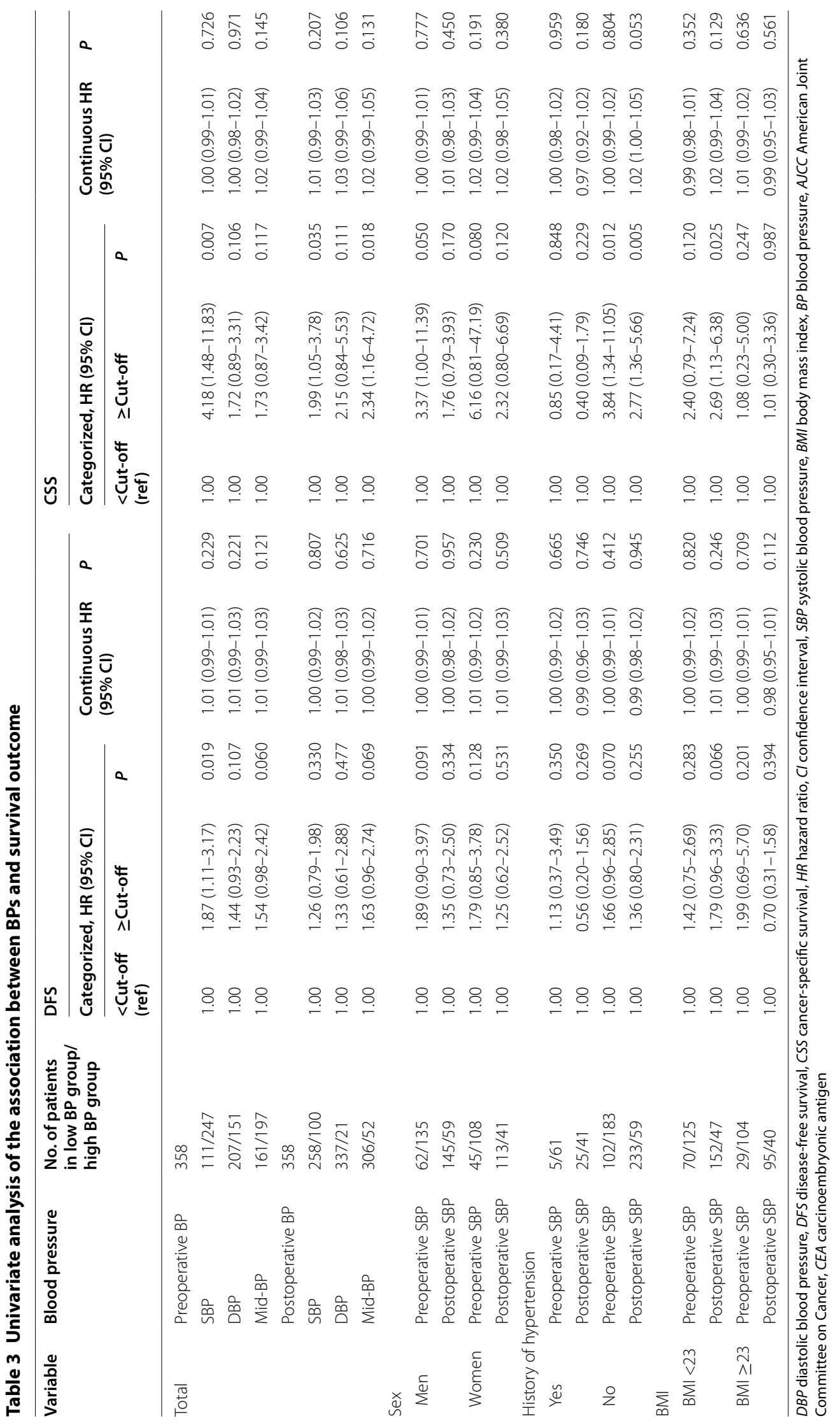


Table 4 Multivariate analysis of prognostic factors for DFS and CSS

\begin{tabular}{llr}
\hline Variable & HR $(\mathbf{9 5} \% \mathbf{C l})$ & $\boldsymbol{P}$ \\
\hline DFS & & \\
Age & $0.98(0.96-0.99)$ & 0.039 \\
AJCC stage III & $5.71(2.44-13.37)$ & $<0.001$ \\
Perineural invasion & $2.17(1.09-4.32)$ & 0.028 \\
Distance from anal verge $\geq 5 \mathrm{~cm}$ & $0.53(0.32-0.85)$ & 0.009 \\
Adjuvant treatment & $0.41(0.23-0.71)$ & 0.002 \\
Preoperative SBP $\geq 120 \mathrm{mmHg}$ & $1.97(1.08-3.60)$ & 0.028 \\
CSS & & \\
AJCC stage III & $7.45(1.65-33.64)$ & 0.009 \\
Preoperative CEA $>5 \mathrm{ng} / \mathrm{mL}$ & $2.18(1.03-4.61)$ & 0.042 \\
Distance from anal verge $\geq 5 \mathrm{~cm}$ & $0.36(0.17-0.77)$ & 0.009 \\
Adjuvant treatment & $0.36(0.17-0.78)$ & 0.010 \\
Preoperative SBP $\geq 120 \mathrm{mmHg}$ & $2.85(1.00-8.25)$ & 0.050 \\
\hline
\end{tabular}

DFS disease-free survival, CSS cancer-specific survival, $H R$ hazard ratio, $C l$ confidence interval, $S B P$ systolic blood pressure, $B M I$ body mass index, $B P$ blood pressure, AJCC American Joint Committee on Cancer, CEA carcinoembryonic antigen

both hypertension and tumorigenesis. Furthermore, factors related to hypertension, such as age, smoking, and alcohol consumption, might contribute to increased cancer mortality. However, these hypotheses and findings could not account for the involvement of high perioperative SBP that is independent of a history of hypertension in cancer mortality. Therefore, we hypothesized that surgical procedures may augment the release of cancer cells into circulation [27], and then high BP in the perioperative period might enable the circulating cancer cells to penetrate blood vessels, which partially contributes to local recurrence, distant metastasis, and cancer-specific death.

Our results indicate that the cancer-specific death risk of high SBP is higher and statistically significant in men and in patients with a low BMI, which is consistent with the findings from previous study of all-site cancer and colorectal cancer [6]. Male sex, BMI, elevated perioperative BP, and hypertension can be related, with a possibility of a more complex pattern among these factors in the risk of cancer-specific death.

Nevertheless, our study does have limitations. First, regarding the subgroup analyses, we were not able to determine the patients' precise overall use of antihypertensive drugs; therefore, the quantification of risks as presented may not be valid. Second, this was a retrospective study and thus was limited by unknown confounders owing to its observational nature, although some variables were controlled. Although BP was predictive in our study, future studies in larger or prospective cohorts are necessary to validate the association.

\section{Conclusions}

This study showed that high preoperative SBP was an independent risk factor for both CSS and DFS and that high postoperative SBP was significantly associated with poor CSS. Furthermore, our subset analyses suggested that the unfavorable effect of high BP is independent of a patient's history of hypertension and use of antihypertensive drugs. Additionally, our results suggest that patients with rectal cancer may get survival benefit from BP control in perioperative care. However, future studies should determine this association and identify the targets of $\mathrm{BP}$ control.

\section{Authors' contributions}

JPW, HCY, and YXL conceived and designed the study. HCY, ZHY, and XLW collected the data. $\mathrm{HCY}, \mathrm{HP}, \mathrm{YXL}, \mathrm{LK}, \mathrm{MJH}$, and $\mathrm{LW}$ analyzed and interpreted the data. $H C Y, Y X L, H P$, and $L W$ drafted the manuscript. JPW revised the manuscript critically for important intellectual content. All authors read and approved the final manuscript.

\section{Author details}

${ }^{1}$ Department of Colon and Rectum Surgery, The Sixth Affiliated Hospital (Guangdong Gastrointestinal and Anal Hospital), Sun Yat-sen University, Guangzhou, Guangdong 510655, P. R. China. ${ }^{2}$ Guangdong Provincial Key Laboratory of Colorectal and Pelvic Floor Disease, The Sixth Affiliated Hospital (Guangdong Gastrointestinal and Anal Hospital), Sun Yat-sen University, Guangzhou, Guangdong 510655, P. R. China.

\section{Acknowledgements}

Support for this study was provided by the National Basic Research Program of China (973 Program) (No. 2015CB554001, JW), the National Natural Science Foundation of China (No. 81472257, YL; No. 81201920, YL; No. 81502022, XW), the Natural Science Foundation of Guangdong Province (No. S2013010013607, YL), the Science and Technology Program of Guangzhou (No. 201506010099, YL), the Fundamental Research Funds for the Central Universities (Sun Yat-sen University) (No. 2015ykzd10, YL; No. 13ykpy37, YL), and Wu Jieping Medical Foundation (320675015173 HY).

\section{Competing interests}

The authors report no proprietary or commercial interest in any product mentioned or concept discussed in this article. The authors declare that they have no competing interests.

Received: 2 August 2015 Accepted: 20 October 2015

Published online: 11 April 2016

References

1. Siegel RL, Miller KD, Jemal A. Cancer statistics, 2015. CA Cancer J Clin. 2015;65:5-29.

2. Chen WQ, Zheng RS, Zhang SW, Zeng HM, Zou XN. The incidences and mortalities of major cancers in China, 2010. Chin J Cancer. 2014;33:402-5.

3. Zhou Q, Li K, Lin GZ, Shen JC, Dong H, Gu YT, et al. Incidence trends and age distribution of colorectal cancer by subsite in Guangzhou, 2000-2011. Chin J Cancer. 2015:34:34.

4. Reimers MS, Zeestraten EC, Kuppen PJ, Liefers GJ, van de Velde CJ. Biomarkers in precision therapy in colorectal cancer. Gastroenterol Rep (Oxf). 2013;1:166-83.

5. Whitworth JA. 2003 World Health Organization (WHO)/International Society of Hypertension (ISH) statement on management of hypertension. J Hypertens. 2003;21:1983-92.

6. Stocks T, Van Hemelrijck M, Manjer J, Bjorge T, Ulmer H, Hallmans G, et al. Blood pressure and risk of cancer incidence and mortality in the metabolic syndrome and cancer project. Hypertension. 2012;59:802-10. 
7. Grossman E, Messerli FH, Boyko V, Goldbourt U. Is there an association between hypertension and cancer mortality. Am J Med. 2002;112:479-86.

8. Schneider BP, Wang M, Radovich M, Sledge GW, Badve S, Thor A, et al. Association of vascular endothelial growth factor and vascular endothelial growth factor receptor-2 genetic polymorphisms with outcome in a trial of paclitaxel compared with paclitaxel plus bevacizumab in advanced breast cancer: ECOG 2100. J Clin Oncol. 2008:26:4672-8.

9. Stocks T, Lukanova A, Johansson M, Rinaldi S, Palmqvist R, Hallmans G, et al. Components of the metabolic syndrome and colorectal cancer risk; a prospective study. Int J Obes (Lond). 2008;32:304-14.

10. Dyer AR, Stamler J, Berkson DM, Lindberg HA, Stevens E. High bloodpressure: a risk factor for cancer mortality. Lancet. 1975;1:1051-6.

11. Wannamethee G, Shaper AG. Blood pressure and cancer in middle-aged British men. Int J Epidemiol. 1996;25:22-31.

12. Peeters PH, van Noord PA, Hoes AW, Grobbee DE. Hypertension, antihypertensive drugs, and mortality from cancer among women. J Hypertens. 1998:16:941-7.

13. Schmoll HJ, Van Cutsem E, Stein A, et al. ESMO consensus guidelines for management of patients with colon and rectal cancer. a personalized approach to clinical decision making. Ann Oncol. 2012;23(10):2479-516.

14. WHO, Expert Consultation. Appropriate body-mass index for Asian populations and its implications for policy and intervention strategies. Lancet. 2004;363:157-63.

15. Lewington S, Clarke R, Qizilbash N, Peto R, Collins R. Age-specific relevance of usual blood pressure to vascular mortality: a meta-analysis of individual data for one million adults in 61 prospective studies. Lancet. 2002:360:1903-13.

16. Chobanian AV, Bakris GL, Black HR, Cushman WC, Green LA, Izzo JL Jr, et al. The seventh report of the Joint National Committee on prevention, detection, evaluation, and treatment of high blood pressure: the JNC 7 report. JAMA. 2003;289:2560-72

17. Deng $Y$, Zhou J, Fang L, Cai Y, Ke J, Xie X, et al. ALDH1 is an independent prognostic factor for patients with stages $\|-I||$ rectal cancer after receiving radiochemotherapy. Br J Cancer. 2014;110:430-4.

18. Park B, Jeong BC, Seo SI, Jeon SS, Choi HY, Lee HM. Influence of body mass index, smoking, and blood pressure on survival of patients with surgically-treated, low stage renal cell carcinoma: a 14-year retrospective cohort study. J Korean Med Sci. 2013;28:227-36.

19. Staessen JA, Fagard R, Thijs L, Celis H, Arabidze GG, Birkenhager WH, et al. Randomised double-blind comparison of placebo and active treatment for older patients with isolated systolic hypertension. The systolic hypertension in Europe (Syst-Eur) trial investigators. Lancet. 1997;350:757-64.

20. Lindholm LH, Anderson H, Ekbom T, Hansson L, Lanke J, Dahlof B, et al. Relation between drug treatment and cancer in hypertensives in the Swedish trial in old patients with hypertension 2: a 5-year, prospective, randomised, controlled trial. Lancet. 2001;358:539-44.

21. Dahlof B, Sever PS, Poulter NR, Wedel H, Beevers DG, Caulfield M, et al. Prevention of cardiovascular events with an antihypertensive regimen of amlodipine adding perindopril as required versus atenolol adding bendroflumethiazide as required, in the Anglo-Scandinavian cardiac outcomes trial-blood pressure lowering arm (ASCOT-BPLA): a multicentre randomised controlled trial. Lancet. 2005;366:895-906.

22. SHEP Cooperative Research Group. Prevention of stroke by antihypertensive drug treatment in older persons with isolated systolic hypertension. Final results of the systolic hypertension in the Elderly Program (SHEP). JAMA. 1991;265:3255-64.

23. James PA, Oparil S, Carter BL, Cushman WC, Dennison-Himmelfarb C, Handler J, et al. 2014 evidence-based guideline for the management of high blood pressure in adults: report from the panel members appointed to the Eighth Joint National Committee (JNC 8). JAMA. 2014;311:507-20.

24. Hamet P. Cancer and hypertension: a potential for crosstalk. J Hypertens. 1997; 15:1573-7.

25. Meyer P. Increased intracellular calcium: from hypertension to cancer. J Hypertens Suppl. 1987:5:S3-4.

26. Norden A, Schersten B, Thulin T, Pero RW, Bryngelsson C, Mitelman F. Letter: hypertension related to D.N.A. repair synthesis and carcinogen uptake. Lancet. 1975;2:1094.

27. Lundy J. Anesthesia and surgery: a double-edged sword for the cancer patient. J Surg Oncol. 1980;14:61-5.

\section{Submit your next manuscript to BioMed Central and we will help you at every step:}

- We accept pre-submission inquiries

- Our selector tool helps you to find the most relevant journal

- We provide round the clock customer support

- Convenient online submission

- Thorough peer review

- Inclusion in PubMed and all major indexing services

- Maximum visibility for your research

Submit your manuscript at www.biomedcentral.com/submit
() Biomed Central 